\title{
Thresholds for oximetry alarms and target range in the NICU: an observational assessment based on likely oxygen tension and maturity
}

Thomas E. Bachman ${ }^{1,2^{*}}$ (D, Narayan P. Iyer ${ }^{3}$, Christopher J. L. Newth ${ }^{4}$, Patrick A. Ross ${ }^{4}$ and Robinder G. Khemani ${ }^{4}$

\begin{abstract}
Background: Continuous monitoring of $\mathrm{SpO}_{2}$ in the neonatal ICU is the standard of care. Changes in $\mathrm{SpO}_{2}$ exposure have been shown to markedly impact outcome, but limiting extreme episodes is an arduous task. Much more complicated than setting alarm policy, it is fraught with balancing alarm fatigue and compliance. Information on optimum strategies is limited.
\end{abstract}

Methods: This is a retrospective observational study intended to describe the relative chance of normoxemia, and risks of hypoxemia and hyperoxemia at relevant $\mathrm{SpO}_{2}$ levels in the neonatal ICU. The data, paired $\mathrm{SpO}_{2}-\mathrm{PaO}_{2}$ and post-menstrual age, are from a single tertiary care unit. They reflect all infants receiving supplemental oxygen and mechanical ventilation during a 3-year period. The primary measures were the chance of normoxemia $\left(\mathrm{PaO}_{2} 50-80\right.$ $\mathrm{mmHg})$, risks of severe hypoxemia $\left(\mathrm{PaO}_{2} \leq 40 \mathrm{mmHg}\right)$, and of severe hyperoxemia $\left(\mathrm{PaO}_{2} \geq 100 \mathrm{mmHg}\right)$ at relevant $\mathrm{SpO}_{2}$ levels.

Results: Neonates were categorized by postmenstrual age: $<33(n=155), 33-36(n=192)$ and $>36(n=1031)$ weeks. From these infants, $26,162 \mathrm{SpO}_{2}-\mathrm{PaO}_{2}$ pairs were evaluated. The post-menstrual weeks (median and IQR) of the three groups were: 26 (24-28) $n=2603 ; 34$ (33-35) $n=2501$; and 38 (37-39) $n=21,058$. The chance of normoxemia (65, 95\%-Cl 64-67\%) was similar across the $\mathrm{SpO}_{2}$ range of $88-95 \%$, and independent of PMA. The increasing risk of severe hypoxemia became marked at a $\mathrm{SpO}_{2}$ of $85 \%(25,95 \%-\mathrm{Cl} 21-29 \%)$, and was independent of PMA. The risk of severe hyperoxemia was dependent on PMA. For infants < 33 weeks it was marked at $98 \% \mathrm{SpO}_{2}(25,95 \%-\mathrm{Cl} 18-33 \%)$, for infants 33-36 weeks at 97\% $\mathrm{SpO}_{2}(24,95 \%-\mathrm{Cl} 14-25 \%)$ and for those $>36$ weeks at $96 \% \mathrm{SpO}_{2}(20,95 \%-\mathrm{Cl} 17-22 \%)$.

Conclusions: The risk of hyperoxemia and hypoxemia increases exponentially as $\mathrm{SpO}_{2}$ moves towards extremes. Postmenstrual age influences the threshold at which the risk of hyperoxemia became pronounced, but not the thresholds of hypoxemia or normoxemia. The thresholds at which a marked change in the risk of hyperoxemia and hypoxemia occur can be used to guide the setting of alarm thresholds. Optimal management of neonatal oxygen saturation must take into account concerns of alarm fatigue, staffing levels, and $\mathrm{FiO}_{2}$ titration practices.

Keywords: Pulse oximetry, Alarm fatigue, Neonatology

\footnotetext{
* Correspondence: TBachman@ME.com

'Department of Biomedical Technology, Faculty of Biomedical Engineering,

Czech Technical University in Prague, Kladno, Czech Republic

'Lake Arrowhead, USA

Full list of author information is available at the end of the article
}

C The Author(s). 2020 Open Access This article is licensed under a Creative Commons Attribution 4.0 International License, which permits use, sharing, adaptation, distribution and reproduction in any medium or format, as long as you give appropriate credit to the original author(s) and the source, provide a link to the Creative Commons licence, and indicate if changes were made. The images or other third party material in this article are included in the article's Creative Commons licence, unless indicated otherwise in a credit line to the material. If material is not included in the article's Creative Commons licence and your intended use is not permitted by statutory regulation or exceeds the permitted use, you will need to obtain permission directly from the copyright holder. To view a copy of this licence, visit http://creativecommons.org/licenses/by/4.0/. The Creative Commons Public Domain Dedication waiver (http://creativecommons.org/publicdomain/zero/1.0/) applies to the data made available in this article, unless otherwise stated in a credit line to the data. 


\section{Background}

Shifts in $\mathrm{SpO}_{2}$ exposure have a profound impact on neonatal outcomes. Control of exposure is associated with the selection of a desired target range, selection of alarm limits as well as nursing compliance with good practices.

Manual titration of $\mathrm{FiO}_{2}$ to address unstable $\mathrm{SpO}_{2}$ is an arduous task. Infants in the NICU typically spend only about half the time in the desired range, and there is significant variation among centers [1]. Nursing intervention is driven by high and low $\mathrm{SpO}_{2}$ alarms, probably more than the prescribed target range. Oximeter alarms are notorious for false positives and are associated with alarm fatigue [2-4]. A persistent low alarm necessitates the need for increased supplemental oxygen to minimize the impact of transient hypoxemia, usually a result of respiratory instability. In contrast, high alarms usually signal the need to titrate the oxygen down following recovery from a marked desaturation. If the alarm limits are too narrow or the response to aggressive, troublesome swings between hypoxemia and hyperoxemia can occur. Further there is little evidence supporting guidelines and general practice with regard to selection of $\mathrm{SpO}_{2}$ alarm limits. Even consensus international guidelines for extremely preterm infants are not consistent. European Guidelines report there is weak evidence to support setting the alarms close to the desired target range [5]. Clearly doing so increases the frequency of false alarms and the potential for alarm fatigue $[3,6]$. The most recent guidelines from the American Academy of Pediatrics, in contrast, suggest looser low alarms are more appropriate [7]. They further suggest that $\mathrm{SpO}_{2}$ alarm limits and target range should not only be decoupled, but also take into account the infant's maturity. Neither guideline integrates the possible impact of differences in averaging period, alarm delay or differences in devices.

In the last two decades studies have focused on the intended $\mathrm{SpO}_{2}$ target ranges for the extremely premature with a resulting evolution of the standard of practice $[1,8]$. The most recent very large studies suggest a higher, narrower target range might be preferred for extremely preterm infants $[5,9]$. This perspective is, however, far from a consensus [8, 10-13]. Evaluations of the optimal $\mathrm{SpO}_{2}$ exposure for more mature infants are lacking. The risks associated with hypoxemia in near term infants are appreciated; however concerns about hyperoxemia have until recently been limited, at least compared to the extremely preterm.

We have developed an extensive $\mathrm{SpO}_{2}-\mathrm{PaO}_{2}$ database from our NICU and previously reported on the magnitude of the change of risk of severe hypoxemia and hyperoxemia across different $\mathrm{SpO}_{2}$ ranges [14]. The aim of this analysis was to see if specific $\mathrm{SpO}_{2}$ levels for selection of high and low alarms and target ranges could be identified based on the difference in the risk of hypoxemia and hyperoxemia and further to determine to what degree these thresholds might change depending on infant maturity.

\section{Methods}

This is a prospectively defined analysis with the aim of describing arterial oxygenation levels $\left(\mathrm{PaO}_{2}\right)$ associated with various possible $\mathrm{SpO}_{2}$ alarm limits and target ranges. The study is based on the paradigm that high and low $\mathrm{SpO}_{2}$ alarm limits should consider the risk of hypoxemia and hyperoxemia independent of the desired $\mathrm{SpO}_{2}$ target range and further consider infant maturity [7].

This study reflects infants in the Neonatal and Infant Critical Care Unit (NICCU) of Children's Hospital Los Angeles. It is a tertiary care referral center affiliated with the Keck School of Medicine of the University of Southern California. The 58-bed NICCU receives transfers from the greater Southern California area. The bioethics review organization at Children's Hospital Los Angeles (CHLA-17-00236) has waived the need for informed consent for aggregate data analysis studies and specifically approved this project.

In a previous publication we described the development of a $\mathrm{SpO}_{2}-\mathrm{PaO}_{2}$ database of infants receiving mechanical ventilator support with supplemental oxygen between August 2012 and July 2015 [14]. The database links arterial blood gas measurements in laboratory records with simultaneous $\mathrm{SpO}_{2}$ data from the patient monitor system. The $\mathrm{SpO}_{2}$ level is the mean of four 30-s readings coincident with the arterial sample. The gestational age from medical records for each infant, along with the date of measurement permitted calculation of post-menstrual age for each sample. The oximeter in the patient monitoring system used Masimo SET technology (Masimo Corporation Irvine, California), with $10 \mathrm{~s}$ averaging. Continuous monitoring of $\mathrm{SpO}_{2}$ is by practice post-ductal, pre-ductal assessments are conducted with another oximeter. Arterial samples were collected when clinically indicated. Umbilical catheters are used in most infants in their first week of life. As a matter of practice after that right radial lines are preferred, but when not possible left radial or posterior tibial lines are placed.

These study parameters were prospectively defined. Normoxemia was defined as $\mathrm{PaO}_{2}$ between 50 and 80 $\mathrm{mmHg}$. Other oxemic levels were defined as severe hypoxemia $\left(\mathrm{PaO}_{2} \leq 40 \mathrm{mmHg}\right)$ and severe hyperoxemia $\left(\mathrm{PaO}_{2} \geq 100 \mathrm{mmHg}\right)$, We also evaluated levels below and above normoxemia $\left(\mathrm{PaO}_{2}<50,>80 \mathrm{mmHg}\right)$. The selection of the severe thresholds was consistent with our previous publication. Also a consensus of the investigators, the potential ranges of $\mathrm{SpO}_{2}$ alarm limits were 85$89 \%$ and $95-98 \%$ and $\mathrm{SpO}_{2}$ target ranges within the envelop of $88-95 \%$. The endpoints were the chance of 
normoxemia, and the risk of the 4 oxemic levels. Based on our previous work, we hypothesized that infant maturity would significantly impact the chance of normoxemia and risk of severe hyperoxemia and but not of severe hypoxemia. We used post-menstrual age (PMA) as the metric of maturity. PMA values were categorized into three groups. These were $<33$ weeks, $33-36$ weeks and $>36$ weeks PMA. We felt that categories would be of more use clinically than a continuous effect. On a post hoc basis we also explored the impact of postnatal age.

Our primary measure was the risk or chance of each of these oxemic categories within the relevant $\mathrm{SpO}_{2}$ range. For the power analysis we assumed a baseline of relevant risk or chance of $25 \%$, and considered sample sizes of $\mathrm{PaO}_{2}$ values for both 150 and 300 in an adjacent $\mathrm{SpO}_{2}$ bins. The range of 150-300 was selected as this was consistent with the numbers of observations in the smaller maturity categories at the $\mathrm{SpO}_{2}$ extremes. Based on this, we determined that there would be an $80 \%$ chance, at the $p<0.05$ level, that we could detect a reduction to $12 \%$ with 150 observations and to $15 \%$ with 300 observations.

We treated each $\mathrm{SpO}_{2}-\mathrm{PaO}_{2}$ pair as an independent observation. We deemed consideration of within patient effects as not only impractical because of the large number of patients, but also inappropriate because of intrapatient sample variability of temperature, $\mathrm{pH}, \mathrm{PaCO}_{2}$ and transfusion timing. Descriptive presentations of continuous data are shown as median and IQR, and of proportions as percent. The primary variables are presented as percentage along with their 95\% confidence intervals of the proportion. Comparison of continuous variables used the Kruskal-Wallis test with Dunn's procedure for pairwise comparisons. Comparisons of proportions were evaluated using the chi-square test, with Maracuilo's procedure for pairwise comparisons. The impact of maturity on each of the three oxemic category parameters was tested by including maturity-category with $\mathrm{SpO}_{2}$, as independent variables, in a logistic regression equation with oxemic risk or chance as the dependent variable. For the exploratory analysis of the effect of postnatal age, we added age to this logistic regression model. A two-tailed $p<0.05$ was considered statistically significant for all comparisons. Statistical tests were conducted with XLSTAT v19.02 (Addinsoft, Paris, France).

\section{Results}

Our data included 26,162 $\mathrm{SpO}_{2}-\mathrm{PaO}_{2}$ observations of infants receiving supplemental oxygen and respiratory support over a 3-year period. Figure 1 provides a graphic overview of the risk of hypoxemia and hyperoxemia across $\mathrm{SpO}_{2}$ levels between 75 and $100 \%$. The risk of each rises dramatically as $\mathrm{SpO}_{2}$ moves from a nominal

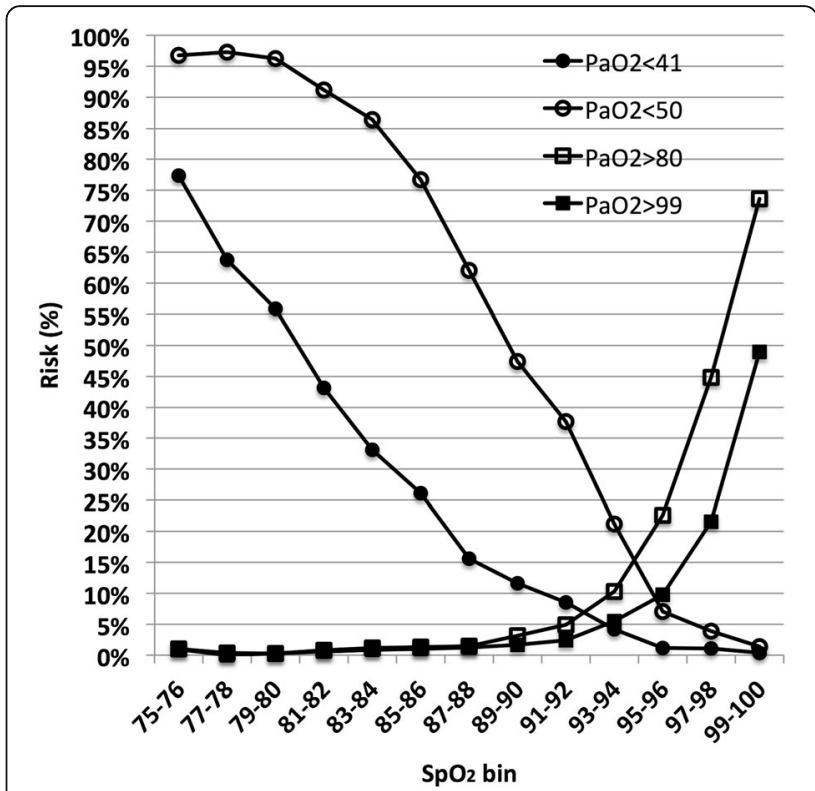

Fig. 1 Risk of Hypoxemia and Hyperoxemia at different levels of $\mathrm{SpO}_{2}$. Circles represent hypoxemia (solid $\mathrm{PaO}_{2}<41 \mathrm{mmHg}$, open $<$ $50 \mathrm{mmHg}$ ). Squares represent hyperoxemia (solid $\mathrm{PaO}_{2}>99 \mathrm{mmHg}$, open $>80 \mathrm{mmHg}$ )

target range. Even when moving within the latter the trade off between hypoxemia and hyperoxemia is obvious. It is also of note that the difference in risk of severe hypoxemia and a $\mathrm{PaO}_{2}<50 \mathrm{mmHg}$, is much larger than the difference between severe hyperoxemia and $\mathrm{a} \mathrm{OaO}_{2}>$ $80 \mathrm{mmHg}$.

For analysis these observations were divided into three groups according to post-menstrual age (PMA). Details characterizing the 3 groups are shown in Table 1 . There were 2603 observations from 155 infants less than 33 weeks PMA, 2501 observations from 192 infants between 33 and 36 weeks PMA and 21,058 observations from 1031 infants greater than 36 weeks PMA. The number of observations per infant was similar among the three groups. The gestational age and postmenstrual age were consistent with the 3 maturity categories. The median $\mathrm{SpO}_{2}$ and $\mathrm{PaO}_{2}$ levels were lower in the group less than 33 weeks PMA. This group also included a higher share of measurements in normoxemia and less in severe hyperoxemia.

The chance of normoxemia was dependent on $\mathrm{SpO}_{2}$ $(p<0.001)$ but not PMA. The chance of normoxemia across the range of $88-95 \% \mathrm{SpO}_{2}$ was $65 \%$ (64-67 95\% CI). The actual chance of normoxemia for 4 different overlapping $\mathrm{SpO}_{2}$ target ranges are shown in Table 2, and were different, specifically slightly lower in the lower ranges $(p<0.001)$. The $\mathrm{PaO}_{2}$ levels for each are also shown in the table and the differences between them are statistically significant $(p<0.001)$. Higher target ranges increase the possibility of higher 
Table 1 Description of Maturity Category Cohorts

\begin{tabular}{|c|c|c|c|c|}
\hline Maturity category & $<33$ PMA & 33-36 PMA & $>36$ PMA & $p$ \\
\hline Subjects (n) & 155 & 192 & 1031 & na \\
\hline Observations (n) & 2603 & 2501 & 21,058 & na \\
\hline Observations/subject (n) & $12(4-22)$ & $9(4-17)$ & $11(4-29)$ & $<0.01$ \\
\hline GA (weeks) & $26(24-28)$ & $34(33-35)$ & $38(37-39)$ & $<0.001$ \\
\hline PMA (weeks) & $28(26-31)$ & $35(34-36)$ & $40(39-43)$ & $<0.001$ \\
\hline Postnatal age (weeks) & $2.1(1.0-3.7)$ & $1.1(0.4-2.3)$ & $2.0(1.0-6.3)$ & $<0.001$ \\
\hline $\mathrm{FiO}_{2}(\%)$ & $45(30-70)$ & $50(35-83)$ & $45(35-70)$ & $<0.001$ \\
\hline $\mathrm{SpO}_{2}(\%)$ & $93(86-97)$ & $96(91-100)$ & $97(87-100)$ & $<0.001$ \\
\hline $\mathrm{PaO}_{2}(\mathrm{mmHg})$ & $55(45-71)$ & $69(50-100)$ & $75(47-112)$ & $<0.001$ \\
\hline $\mathrm{PaO}_{2} \leq 40(\%)$ & $15 \%$ & $12 \%$ & $15 \%$ & $<0.001^{*}$ \\
\hline $\mathrm{PaO}_{2}$ 50-80 (\%) & $43 \%$ & $33 \%$ & $24 \%$ & $<0.001^{*}$ \\
\hline $\mathrm{PaO}_{2} \geq 100(\%)$ & $10 \%$ & $25 \%$ & $32 \%$ & $<0.001^{*}$ \\
\hline $\mathrm{PaO}_{2} / \mathrm{FiO}_{2}$ & $130(81-192)$ & $161(90-240)$ & $167(93-263)$ & $<0.001$ \\
\hline $\mathrm{PaCO}_{2}(\mathrm{mmHg})$ & $45(39-52)$ & $45(39-53)$ & $45(40-52)$ & ns \\
\hline $\mathrm{pH}$ & $7.34(7.28-7.40)$ & $7.36(7.30-7.41)$ & $7.39(7.34-7.43)$ & $<0.001$ \\
\hline
\end{tabular}

Statistical comparisons (Kruskal-Wallis and chi-square* as appropriate) among the 3 maturity categories are shown in Table

levels of $\mathrm{PaO}_{2}$, but decrease the possibility of lower levels. The variation (interquartile range) of $\mathrm{PaO}_{2}$ levels among the 4 is similar.

The risk of hypoxemia $\left(\mathrm{PaO}_{2}<50\right.$ and $\left.<41 \mathrm{mmHg}\right)$ was independent of PMA but not $\mathrm{SpO}_{2}(\mathrm{p}<0.001)$. The risks at different potential alarm levels are shown in Table 3. The risks are not different at settings of 89, 88, and $87 \% \mathrm{SpO}_{2}$ for either $\mathrm{PaO}_{2}<50 \mathrm{mmHg}$ or $<41 \mathrm{mmHg}$. They were both markedly higher at 86 and $85 \% \mathrm{SpO}_{2} .(p<0.01)$ At these levels the risk of severe hypoxemia $(<41 \mathrm{mmHg})$ was marked; at $86 \%$ $\mathrm{SpO}_{2}$ (risk: $20 \%(16-24,95 \% \mathrm{CI})$ ) and at $85 \% \mathrm{SpO}_{2}$ (risk: $25 \%(21-29,95 \% \mathrm{CI})$ ). The changes in risks are consistent with the changes in the $\mathrm{PaO}_{2}$ also shown in the table. The variation (interquartile range) of $\mathrm{PaO}_{2}$ levels is similar.

The risk of hyperoxemia $\left(\mathrm{PaO}_{2}>80\right.$ and $>99$ $\mathrm{mmHg}$ ) was significantly different among the 3 PMA categories $(p<0.001)$ and within each category among the $\mathrm{SpO}_{2}$ levels $(p<0.001)$. The actual risks at different potential alarm levels are shown in Table 4 for each maturity category. The potential point of marked increase in the risk of a $\mathrm{PaO}_{2}>80$ and $>99 \mathrm{mmHg}$ were different for the three maturity categories. With regard to severe hyperoxemia, for those $<33$ weeks it was a reading of $98 \% \mathrm{SpO}_{2}$ (risk: 25\% (18-33, 95\% $\mathrm{CI})$ ), which was significantly higher than at 95 and $96 \% \mathrm{SpO}_{2}(p<0.05)$. It was a $\mathrm{SpO}_{2}$ reading of $97 \%$ for those 33-36 weeks (risk: 20\% (14-25\%, 95\% CI)), which was not significantly higher than 95 and $96 \%$. A reading of $96 \%$ for those $>36$ weeks ( $20 \%$ risk: (17$22,95 \% \mathrm{CI})$ ), and the difference between all pairs was statistically significant $(p<0.001)$. A point of demarcation for the risks of $\mathrm{PaO}_{2}>80 \mathrm{mmHg}$ is $1 \mathrm{SpO} 2$ level lower for each of the 3 PMA categories. The changes in risks are consistent with the changes in the $\mathrm{PaO}_{2}$ levels also shown in the table. The variation (interquartile range) of $\mathrm{PaO}_{2}$ levels is similar except at $98 \% \mathrm{SpO}_{2}$, which is wider.

Our exploratory analysis determined that postnatal age was an independent predictor of chance of normoxemia $(p<0.001)$ and risk of severe hyperoxemia $(p<0.001)$, but not severe hypoxemia. With increasing age the chance of normoxemia increased while the risk of hyperoxemia decreased. However the size of the effect predicted by the regression equation was quite small; that is changes of $+0.7 \%$ (normoxemia) and $-0.6 \%$ (severe hyperoxemia) for each week of age.

Table 2 Chance of Normoxemia at Potential $\mathrm{SpO}_{2}$ Target Ranges

\begin{tabular}{lllll}
\hline Target Range & $88-92 \mathrm{SpO}_{2}$ & $89-93 \mathrm{SpO}_{2}$ & $90-94 \mathrm{SpO}_{2}$ & $91-95 \mathrm{SpO}_{2}$ \\
\hline $\mathrm{n}$ & 2357 & 2946 & 3716 & 4584 \\
Chance $50-80(\%)$ & $59 \%(57-61 \%)$ & $63 \%(61-65 \%)$ & $67 \%(65-68 \%)$ & $68 \%(67-70 \%)$ \\
$\mathrm{PaO}_{2}(\mathrm{mmHg})$ & $53(47-61)$ & $55(48-64)$ & $58(51-68)$ & $62(53-73)<0.001$ \\
\hline
\end{tabular}

Normoxemia defined as $\mathrm{PaO}_{2}$ of $50-80 \mathrm{mmHg}$. Chance shown as a percentage $(95 \% \mathrm{Cl}$ of proportion), differences evaluated with chi-square test. PaO levels show as median (IQR) differences evaluated with Kruskal-Wallis test 
Table 3 Risk of Hypoxemia at Potential Low $\mathrm{SpO}_{2}$ Alarm Limits

\begin{tabular}{lllllll}
\hline & $89 \% \mathrm{SpO}_{2}$ & $88 \% \mathrm{SpO}_{2}$ & $87 \% \mathrm{SpO}_{2}$ & $86 \% \mathrm{SpO}_{2}$ & $85 \% \mathrm{SpO}_{2}$ & $p$ \\
\hline $\mathrm{n}$ & 279 & 251 & 331 & 389 & 444 & \\
$\mathrm{Risk}<50(\%)$ & $46 \%(40-50 \%)$ & $49 \%(40-55 \%)$ & $50 \%(45-56 \%)$ & $74 \%(70-78 \%)$ & $71 \%(66-75 \%)$ & $<0.001$ \\
$\mathrm{Risk}<41(\%)$ & $13 \%(9-17 \%)$ & $10 \%(06-14 \%)$ & $11 \%(8-15 \%)$ & $20 \%(16-24 \%)$ & $25 \%(21-29 \%)$ & $<0.001$ \\
$\mathrm{PaO}_{2}(\mathrm{mmHg})$ & $51(44-57)$ & $50(44-54)$ & $49(44-55)$ & $46(42-50)$ & $46(40-50)$ & $<0.001$ \\
\hline
\end{tabular}

Severe hypoxemia defined as $\mathrm{PaO}_{2}$ of $<41 \mathrm{mmHg}$. Risks shown as a percentage $(95 \% \mathrm{Cl}$ of proportion), differences evaluated with chi-square test. PaO among all levels presented as median (IQR), with differences in evaluated with Kruskal-Wallis test

\section{Discussion}

We evaluated a large database of neonatal $\mathrm{SpO}_{2}-\mathrm{PaO}_{2}$ observations paired with infant postmenstrual age. Our aim was to provide additional guidance to support the selection of $\mathrm{SpO}_{2}$ alarm levels and target ranges for neonates receiving supplemental oxygen. We identified a $\mathrm{SpO}_{2}$ range consistent with normoxemia, and showed how a target range could shift depending on a preference for avoiding higher or lower levels of $\mathrm{PaO}_{2}$. We showed that the risk of hyperoxemia and hypoxemia increases exponentially as $\mathrm{SpO}_{2}$ moves toward extremes. We found that the risk of severe hypoxemia does not become marked until a level well below common low alarm settings. Finally we found that the risk of severe hyperoxemia becomes marked at different levels depending on postmenstrual age and importantly at thresholds not consistent with standard practices. This report is, to our knowledge, the first to document these perspectives.

We evaluated four overlapping target ranges, each 4 wide with mid points of $90,91,92$, and $93 \% \mathrm{SpO}_{2}$. Our data showed that there was a similar chance of normoxemia across these potential target ranges, but slightly favoring the higher target ranges. This consistency also suggests that a wider target range, even 88-95\% $\mathrm{SpO}_{2}$, would maintain a similar chance of normoxemia, but could be easier to maintain. A wider range at the low end has been suggested for extremely preterm infants $[10,11]$, in contrast to the European guidelines that recommend a higher target range [5]. Two recent reports of practices in Europe and the US reported that most target ranges were within this wider envelop, though more often narrower than seven but rarely 4 or less $[1,8]$.

Our analysis did not identify an effect related to maturity associated with normoxemia as we had expected. However our hypothesis was based on risk data of extreme $\mathrm{PaO}_{2}$ levels $(<41$ and $>99 \mathrm{mmHg})$ at $\mathrm{SpO}_{2}$ levels between 90 and $95 \%$, which is different from our normoxemia criteria $\left(\mathrm{PaO}_{2} 50-80 \mathrm{mmHg}\right)$. Further the information about likely $\mathrm{PaO}_{2}$ values, consideration of which might align with maturity, ought to be useful in selecting a target range within these boundaries [11]. A

Table 4 Risk of Hyperoxemia at potential High $\mathrm{SpO}_{2}$ Alarm Limits by Maturity Category

\begin{tabular}{|c|c|c|c|c|c|}
\hline & $95 \% \mathrm{SpO}_{2}$ & $96 \% \mathrm{SpO}_{2}$ & $97 \% \mathrm{SpO}_{2}$ & $98 \% \mathrm{SpO}_{2}$ & $p$ \\
\hline \multicolumn{6}{|l|}{$\mathrm{PMA}<33$} \\
\hline$n$ & 175 & 154 & 150 & 126 & \\
\hline Risk > $80(\%)$ & $18 \%(12-23 \%)$ & $12 \%(7-18 \%)$ & $37 \%(30-45 \%)$ & $45 \%(34-54 \%)$ & $<0.001$ \\
\hline Risk > 99 (\%) & $7 \%(3-11 \%)$ & $4 \%(1-7 \%)$ & 14\% (8-20\%) & $25 \%(18-33 \%)$ & $<0.001$ \\
\hline $\mathrm{PaO}_{2}$ & $63(54-73)$ & $62(54-73)$ & $71(60-88)$ & $80(63-100)$ & $<0.001$ \\
\hline \multicolumn{6}{|l|}{ PMA 33-36 } \\
\hline$n$ & 156 & 172 & 190 & 225 & \\
\hline Risk > $80(\%)$ & $28 \%(0.21-0.35)$ & $26 \%(19-32 \%)$ & $0.43(36-50 \%)$ & $0.61(54-67 \%)$ & $<0.001$ \\
\hline Risk > $99(\%)$ & 10\% (6-15\%) & 13\% (8-18\%) & $20 \%(14-25 \%)$ & $34 \%(28-40 \%)$ & $<0.001$ \\
\hline $\mathrm{PaO}_{2}$ & $68(61-81)$ & $70(62-81)$ & 79 (67-92) & 86 (73-108) & $<0.001$ \\
\hline \multicolumn{6}{|l|}{ PMA $>36$} \\
\hline$n$ & 959 & 1156 & 1483 & 1729 & \\
\hline Risk > $80(\%)$ & $28 \%(25-31 \%)$ & $42 \%(39-45 \%)$ & $56 \%(53-58 \%)$ & $70 \%(68-72 \%)$ & $<0.001$ \\
\hline Risk > 99 (\%) & $14 \%(10-14 \%)$ & $20 \%(17-22 \%)$ & $28 \%(26-30 \%)$ & $42 \%(41-45 \%)$ & $<0.001$ \\
\hline $\mathrm{PaO}_{2}$ & $70(61-83)$ & $76(65-93)$ & $84(70-103)$ & $94(78-124)$ & $<0.001$ \\
\hline
\end{tabular}

Severe hyperoxemia defined as $>99 \mathrm{mmHg}$. Differences in risk evaluated with chi-square test. $\mathrm{PaO}_{2}$ presented as median (IQR) with differences evaluated with Kruskal-Wallis test. $\mathrm{PaO}_{2}$ pairs within each maturity category are also statistically different $(\mathrm{p}<0.001)$ except the difference between 95 and $96 \%$ SpO $\mathrm{O}_{2}$ in both the $<33$ weeks and 33-36 weeks groups 
clinical aversion to higher or lower $\mathrm{PaO}_{2}$ levels is reasonable. The consideration of a trade off of high and low oxygen exposure is supported by a landmark evaluation comparing the long term outcomes of nearly 5000 extremely preterm infants randomized to one of two $\mathrm{SpO}_{2}$ target ranges (85-89\% or 91-95\%) [9]. It found the high range was associated with increases in severe retinopathy of prematurity and more likely need for supplemental oxygen at 36 weeks PMA, but lower levels of necrotizing enterocolitis and death.

Alarm fatigue in the NICU is a serious problem. Pulse oximetry, while an essential tool, generates the most false alarms and is the alarm least likely to be associated with an actionable nursing intervention $[2,3,15]$. It is not uncommon with unstable infants to experience a $\mathrm{SpO}_{2}$ alarm every few minutes, while an intervention is often only warranted every $5-10 \mathrm{~min}$. Faced with this dilemma nurses have been shown to disregard alarm policy [1]. Attention to selection of reasonable alarm settings (delay, and level) as well as sensor/probe integrity, can impact the frequency of alarms not needing intervention $[16,17]$. However setting alarms, whether by policy or practice, to avoid excessive frequency must also consider the risk of missing or delaying response to important events. Policy and practice must balance the need to find an acceptable medium to balance the risks associated with each. Our data provide $\mathrm{SpO}_{2}$ thresholds that are associated with marked hyperoxemia and hypoxemia. It is reasonable to consider a buffer zone between the alarm setting and the level of $\mathrm{SpO}_{2}$ concern. In addition, many events are short and it is standard practice to set the alarm delay to avoid these transient events not needing intervention. Correspondingly it seems appropriate to set a longer alarm delay when the buffer zone is wider.

Our data indicate that the risk of hypoxemia is not related to maturity and is not marked until the $\mathrm{SpO}_{2}$ is at $86 \%$ or $85 \%$, at which point the risk is increasing exponentially. In contrast we found no relevant difference in risk at levels between 87 and $89 \%$. Setting the low alarm between 87 and $89 \% \mathrm{SpO}_{2}$ would create a buffer but at the expense of increased false alarms and alarm fatigue, without a compensating longer alarm delay. A recent analysis has determined that episodes that are significantly lower $\left(<80 \% \mathrm{SpO}_{2}\right)$ and prolonged $(>60 \mathrm{~s})$ are related to bad outcomes [18]. However, we speculate that episodes of $\mathrm{SpO}_{2}$ with a nadir between 87 and $89 \%$ even if prolonged, would not have a clinical impact, because of the low risk of severe hypoxemia. Finally, based on an audit of extremely preterm infants in 83 NICUs, Hagadorn et al. reported good compliance with low $\mathrm{SpO}_{2}$ alarm unit guidelines, but provided no related details on the actual settings [1].
In preterm infants we found the risk of hyperoxemia did not become marked until $\mathrm{SpO}_{2}$ reached $97-98 \%$ in those < 33 weeks PMA and those 33-36 weeks PMA. This is higher than the most recent recommendations for setting the high $\mathrm{SpO}_{2}$ alarm around 95\% in extremely preterm infants $[5,7,10]$. Such a lower setting could be appropriate with two difference rationales. It could be considered an appropriate buffer zone. But it certainly would increase false positive alarms, without a compensating longer alarm delay. It might also be appropriate if the goal was to avoid $\mathrm{PaO}_{2}$ levels approaching 80 $\mathrm{mmHg}$, in alignment with a lower target range. Consistent with this likely excessive false positive rate from tighter high alarms, Hagadorn reported only 63\% compliance with high $\mathrm{SpO}_{2}$ alarm unit guidelines [1].

In contrast to preterm infants, we found that the risk of hyperoxemia, $\mathrm{PaO}_{2}>80$ and $>99 \mathrm{mmHg}$, in infants $>$ 36 weeks PMA was marked at a $\mathrm{SpO}_{2}$ of $96 \%$. While reports of guidelines are sparse $[19,20]$, it is our impression that upper alarms for near term populations are often set much higher than $96 \%$. This practice provides no buffer zone and certainly increases false negatives that could increase clinical risk of hyperoxemia. The concern about the risks associated with hyperoxemia in near term infants is less prevalent than in preterms. Nevertheless, hyperoxemia in children and adults has been associated with morbidity and mortality [21, 22] and it is reasonable to project these risks to near term infants.

The shift of the oxy-hemoglobin dissociation curve with increasing maturity that one would anticipate, was evident in high levels of $\mathrm{SpO}_{2}$ but not at moderate and low levels. While the predicted shift in the $\mathrm{SaO}_{2}-\mathrm{PaO}_{2}$ relationship is characterized in a shift of $\mathrm{P} 50$, it is understandable that the smaller predicted shifts in $\mathrm{SpO}_{2}$ at lower levels would be muted. The lack of precision and bias of the pulse oximeter, especially in these ranges, as well as other factors such as local perfusion are documented [23]. The transition from fetal to adult hemoglobin is quite predicable over a couple months of life in healthy neonates, but we did not identify a meaningful impact associated with postnatal age. However the transition from fetal hemoglobin is affected by treatment and disease severity. Transfusions have a marked effect [24-26]. Our study population, all transferred for a higher level of care, commonly were transfused. Accordingly, transfusion naive infants would be shifted more to the left [14]. Such a shift would reduce the risk of hyperoxemia.

This study's design has several limitations. First the $\mathrm{PaO}_{2}$ thresholds we used for hypoxemia, normoxemia and hyperoxemia, while generally accepted, have not been validated with regard to outcome risk. It is unlikely they ever will be. There is a need for and a growing body 
of data correlating $\mathrm{SpO}_{2}$ exposure and outcomes. Of particular interest is a pending analysis of the impact of the actual, rather than assigned, $\mathrm{SpO}_{2}$ exposure in the NeOProM population [9]. We speculate that these interpretations will be easier with a better understanding of the relationship between $\mathrm{PaO}_{2}$ and $\mathrm{SpO}_{2}$. Other factors such as small for gestational age and hemoglobin level as well as cerebral and intestinal oxygenation are also relevant. Second, the study is observational. The location of the $\mathrm{SpO}_{2}$ sensor and site of arterial sampling were not controlled. It is likely that some of the paired comparisons do not reflect pre-ductal assessment. This could increase the variance, but we do not think this would have a relevant effect on the bias of the risk (median values). Third, we categorized the hyperoxemic risk into three PMA groups. These are reasonable groupings, but it is probable that the effect is somewhat continuous with increasing maturity, but certainly not strictly categorical.

Whether using these results to design research or to evaluate unit guidelines, several generalizability issues should be considered. The first is comparabilty to our study population. Our unit is referral based, with all infants transferred in for tertiary care. After intervention and recovery infants are often returned when they only need low levels of inspired oxygen and minimal pressure support. As reported their supplemental oxygen requirements are quite high. Also previously noted, as a result of transfusions, their oxy-hemoglobin relationship is shifted to right. Illustrative of this, in our least mature cohort we identified an incidence of severe hyperoxemia more than 10 times higher than that reported in a more traditional inborn population during the first week of life [27]. Another important consideration is the averaging and alarm delay settings on the oximeter. One large study confirmed the clinical relevance of these settings [28]. They documented a marked decrease in the incidence of severe hypoxemic events with increasing averaging time, and also demonstrated that it was associated with increased duration of episodes. They recommended using shorter averaging times and longer delays. Finally the oximeter measurement itself must be considered. Our data reflect a good bit of scatter in the $\mathrm{PaO}_{2}$ at each $\mathrm{SpO}_{2}$ level. Sources of the scatter seen with $\mathrm{SpO}_{2}$ monitoring are well described $[13,29]$. .Consideration of differences in oximeter brands, and models should be considered as well. Our group previously reported no difference in bias between the Massimo and Nellcor devices across the range of saturations in the PICU, but did identify a problem with the use of inappropriate sensors [23]. Of more potential relevance, a difference between the Massimo and Nellcor oximeters has been reported in the $\mathrm{SpO}_{2}$ range of $87-90 \%$ [30]. While this difference is within the device's $3 \%$ accuracy specifications, it might well effect a decision about selecting a lower target range, or the low $\mathrm{SpO}_{2}$ alarm setting.

\section{Conclusion}

We provide quantification of the rate at which the risk of hyperoxemia and hypoxemia increase exponentially as $\mathrm{SpO}_{2}$ moves towards extremes, and how it is affected by maturity. Postmenstrual age influences the threshold at which the risk of hyperoxemia became pronounced, but PMA did not alter the threshold for hypoxemia or normoxemia. The thresholds at which a marked change in the risk of hyperoxemia and hypoxemia occur can be used to guide the setting of alarm thresholds. These findings support reconsideration of common alarm treshold practices. In extreme preterm infants, but not in more mature infants, high $\mathrm{SpO}_{2}$ alarms may be set higher than $96 \%$. Likewise low $\mathrm{SpO}_{2}$ alarms may be set lower than $89 \% . \mathrm{SpO}_{2}$ targeting ranges may be selected within the range of $88-95 \% \mathrm{SpO}_{2}$. Optimal management of neonatal oxygen saturation must take into account concerns of alarm fatigue, staffing levels, and $\mathrm{FiO}_{2}$ titration practices. Integration of these factors should be evaluated in quality improvement programs.

\section{Abbreviations \\ $\mathrm{FiO}_{2}$ : Fraction of inspired oxygen; $\mathrm{SpO}_{2}$ : Arterial oxygen saturation measured noninvasively; $\mathrm{NICU}$ : Neonatal intensive care unit; $\mathrm{PaO}_{2}$ : Arterial partial pressure of oxygen $(\mathrm{mmHg}) ; \mathrm{PaCO}_{2}$ : Arterial partial pressure of carbon dioxide (mmHg); PMA: Post-menstrual age (weeks)}

\section{Acknowledgements \\ None.}

Scientific (medical) writers

Not applicable.

Third party submissions

Not applicable.

\section{Authors' contributions}

TB was responsible for the conception of the study, the data analysis and initial draft of the manuscript. CN and NI collected the data. The authors (TB, $\mathrm{NI}, \mathrm{CN}, \mathrm{PR}, \mathrm{RK}$ ) critically reviewed and approved the manuscript and agree to be accountable for all aspects of the project.

\section{Funding}

There was no funding provided to support the planning, implementation, analysis or manuscript development.

\section{Availability of data and materials}

The data sets generated and analyzed during this study are not currently publically available, but are available from the corresponding author on reasonable request.

Ethics approval and consent to participate The bioethics review organization at Children's Hospital Los Angeles (CHLA17-00236) has waived the need for informed consent for aggregate data analysis studies and specifically approved this project.

Consent for publication

Not applicable. 


\section{Competing interests}

The authors declare they have no competing interests.

\section{Author details}

'Department of Biomedical Technology, Faculty of Biomedical Engineering, Czech Technical University in Prague, Kladno, Czech Republic. ${ }^{2}$ Lake Arrowhead, USA. ${ }^{3}$ Fetal and Neonatal Institute, Children's Hospital Los Angeles, University of Southern California Keck School of Medicine, Los Angeles, CA, USA. ${ }^{4}$ Department of Anesthesiology and Critical Care Medicine, Children's Hospital Los Angeles, University of Southern California Keck School of Medicine, Los Angeles, CA, USA.

Received: 12 December 2019 Accepted: 23 June 2020

Published online: 27 June 2020

\section{References}

1. Hagadorn JJ, Sink DW, Buus-Frank ME, et al. Alarm safety and oxygen saturation targets in the Vermont Oxford network iNICQ 2015 collaborative. J Perinatol. 2017;37:270-6.

2. Bitan $Y$, Meyer J, Shinar D, Zmora E. Nurses' reactions to alarms in a neonatal intensive care unit. Cogn Tech Work. 2004;6:239-46.

3. Ketko A, Martin C, Nemshak M, et al. Balancing the tension between hyperoxia prevention and alarm fatigue in the NICU. Pediatrics. 2015;136(2): 496-504.

4. Johnson KR, Hagadorn JJ, Sink DW. Alarm safety and alarm fatigue. Clin Perinatol. 2017:44:713-28.

5. Sweet DG, Carnielli V, Greisen G, et al. European consensus guidelines on the management of neonatal respiratory distress syndrome in preterm infants- 2019 update. Neonatology. 2019;114(2):432-50.

6. Lansdowne K, Strauss DG, Scully CG. Retrospective analysis of pulse oximeter alarm settings in an intensive care unit patient population. BMC Nurs. 2016;15:36

7. Cummings JJ, Polin RA. Committee on fetus and newborn. Oxygen targeting in extremely low birth weight infants. Pediatrics. 2016;138(2): e20161576.8.

8. Huizing MJ, Villamor E, Vento M, Villamor E. Pulse oximetry saturation target for preterm infants: a survey among European neonatal intensive care units. Eur J Pediatr. 2017;176(1):51-6.

9. Askie LM, Darlow BA, Finer N, et al. Association between oxygen saturation targeting and death or disability in extremely preterm infants in the neonatal oxygenation prospective meta-analysis collaboration. JAMA. 2018; 319(21):2190-201.

10. Sola A, Golombek S, Montes-Bueno MT, et al. Safe oxygen saturation targeting and monitoring in preterm infants: can we avoid hypoxia and hyperoxia? Acta Paediatr. 2014;103:1009-18.

11. Cayabyab R, Arora V, Wertheimer F, et al. Graded oxygen saturation targets and retinopathy of prematurity in extremely preterm infants. Pediatr Res. 2016:80(3):401-6.

12. Raffay TM, Walsh MC. Pulse oximetry targets in extremely premature infants and associated mortality: one-size may not fit all. J Nat Sci. 2018:4(6):e508.

13. Cummings JJ, Lakshminrusimha S. Oxygen saturation targeting by pulse oximetry in the extremely low gestational age neonate: a quixotic quest. Curr Opin Pediatr. 2017;29(2):153-8.

14. Bachman TE, Newth CJL, lyer NP, et al. Hypoxemia and hyperoxemic likelihood in pulse oximetery ranges: NICU observational study. Arch Dis Child Fetal Neonatal Ed. 2019;104(3):F244-79.

15. Bonafide CP, Localio AR, Holmes, et al. Video Analysis of Factors Associated With Response Time to Physiologic Monitor Alarms in a Children's Hospital. JAMA Pediatr. 2017:171(6):524-31.

16. Warakomska M, Bachman TE, Wilinska M. Evaluation of two SpO2 alarm strategies during automated $\mathrm{FiO} 2$ control in the NICU: a randomized crossover study. BMC Pediatr. 2019;19(1):142.

17. Johnson KR, Hagadorn JJ, Sink DW. Reducing alarm fatigue in two neonatal intensive care units through a quality improvement collaboration. Am J Perinatol. 2018;35(13):1311-8.

18. Poets CF, Roberts RS, Schmidt B, et al. Association between intermittent hypoxemia or bradycardia and late death or disability in extremely preterm infants. JAMA. 2015:314:595-603.

19. Austin N. Practical recommendations for oxygen saturation targets for newborns cared for in neonatal units. New Zealand: Newborn Clinical Network Clinical Reference Group; 2017.
20. Pilgrim S. Monitoring of oxygen saturation levels in the newborn in midwifery setting. Clinical Guidelines. 2018;NHS 04220.

21. Numa A, Aneja $H$, Awad J, et al. Admission hyperoxia is a risk factor for mortality in pediatric intensive care. Pediatr Crit Care Med. 2018 Aug;19(8): 699-704.

22. Aggarwal N, Brower R, Hager D, et al. Oxygen exposure resulting in arterial oxygen tensions above the protocol goal was associated with worse clinical outcomes in acute respiratory distress syndrome. Crit Care Med. 2018;46(4): 517-24.

23. Ross PA, Newth CJL, Khemani R. Accuracy of pulse oximetry in children. Pediatrics. 2014:133:22-9.

24. Bard H, Lachance C, Widness JA, Gagnon C. The reactivation of fetal hemoglobin synthesis during anemia of prematurity. Pediatr Res. 1994;36(2): 253-6.

25. De Halleux $V$, Truttmann A, Gagnon Bard $H$. The effect of blood transfusion on the hemoglobin oxygen dissociation curve of very early preterm infants during the first week of life. Semin Perinatol. 2002;26(6):411-5.

26. Shiao SY. Effects of fetal hemoglobin on accurate measurements of oxygen saturation in neonates. Perinat Neonatal Nurs. 2005;19(4):348-61.

27. Quine D, Stenson BJ. Arterial oxygen tension ( $\mathrm{PaO} 2)$ values in infants $<29$ weeks of gestation at currently targeted saturations. Arch Dis Child Fetal Neonatal Ed. 2009:94:F51-3.

28. McClure C, Jang SY, Fairchild K. Alarms, oxygen saturations, and SpO2 averaging time in the NICU. J Neonatal Perinatal Med. 2016;9(4):357-62.

29. Lakshminrusimha S, Manja V, Mathew B, Suresh GK. Oxygen targeting in preterm infants: a physiological interpretation. J Perinatol. 2015;35(1):8-15.

30. Johnson ED, Boyle B, Juszczak E, et al. Oxygen targeting in preterm infants using the Masimo SET radical pulse oximeter. Arch Dis Child Fetal Neonatal Ed. 2011;96:F429-33.

\section{Publisher's Note}

Springer Nature remains neutral with regard to jurisdictional claims in published maps and institutional affiliations.
Ready to submit your research? Choose BMC and benefit from:

- fast, convenient online submission

- thorough peer review by experienced researchers in your field

- rapid publication on acceptance

- support for research data, including large and complex data types

- gold Open Access which fosters wider collaboration and increased citations

- maximum visibility for your research: over $100 \mathrm{M}$ website views per year

At $\mathrm{BMC}$, research is always in progress.

Learn more biomedcentral.com/submissions 